\title{
The Effective Methods of Track and Field Training in Ordinary College and University
}

\author{
Meili Wang ${ }^{1}$, Yuqin Huan ${ }^{2}$ \\ ${ }^{1}$ Shandong Business and Technology University \\ ${ }^{2}$ Qingdao Technological University Qindao College
}

Keywords: Track, Field Training, sports.

\begin{abstract}
As an important part of college sports, track and field sports are related to the comprehensive strength of colleges and universities and the quality of physical education. In recent years, although the track and field training in ordinary university has made some achievements and progress, there are still some shortcoming. Combined with the meaning, characteristics, value and the status of track and field sports in ordinary colleges and universities, this paper analyzes the characteristics and problems of track and field training in colleges and universities and puts forward the corresponding measures to improve the effect and quality of track and field training.
\end{abstract}

\section{Introduction}

Track and field sports is the generic terms of the track games, field games and all-around race. Among them, "field game" mainly refers to jumping, throwing and other sports which measure the results through the jumping height and throwing distance respectively. "Track game" mainly refers to the walking races and running, which measure the performance through the length of time. In addition to field races, track races, walking races, road races and cross-country races, the track and field competition also includes "decathlon", which is by the part of the field, track composition.

(1) as the basic skills of human life, walking, running, jumping, throwing is the most basic forms of track and field sports. And these skills have subtle relationship with sports. It can be said that these basic skills of human bring the advantages and convenience to track and field sports.(2) Track and field sports do not only have individuality, its masses basis is also very broad. In addition to the relay race, most participates of track and field sports are in unit of individual and the group performance is integrated by personal performance and relay performance. (3) There are no conditions for track and field sports. There is no limit on age, gender and other factors. And the track and field competition can be held on the beach, roads, grass and other areas. (4) The different sports items in the track and field sports have different requirements for the athletes' physical function and psychological quality.

(2)It can help people to achieve all-round development of physical quality and promote human immunity and disease resistance. According to the survey research, it is found that track and field sports can improve people's physical fitness. People who keep on walking and running exercise perform relatively well in all aspects of daily life and have better immunity and environmental adaptability. Compared with other people, those who adhere to long-distance race exercise have better aerobic metabolism, which is conducive to the heart and blood metabolism and circulation, improving lung capacity. (2) It can help to exercise people's will. Research of sports psychology found that track and field sports, as important parts of sports activities, can help people to build up willpower, so that people become brave, decisive and tough.

In recent years, on the contrary to continuous improving living standard, many people are in the sub-health status. Therefore, to strengthen the physical exercise has become a trend. As the "mother of sports" track and field sports become the most popular form of sports because of its own advantages and fitness value. Also, it is seen as an important way of exercise at school to improve the physical and psychological performance of students. In addition, the tack and field training in 
colleges and universities is conducive to promoting students to understand the Olympic spirit. Therefore, track and field training in colleges and universities are closely related to the whole country and even the national sports.

\section{Characteristics of Track and Field Training in Ordinary Colleges and Universities}

The main reason of this feature is that colleges and universities can not guarantee the systematic and coherence of training tasks due to that many ordinary college students put most energy on the study of professional knowledge and spend spare time in completing track and field training. It can also be influenced by examinations and holidays. There is a big gap between the professional training team and the training in ordinary colleges and universities about areas and facilities, operating mechanism and nutritional supply and so a lot of athletes step backward.

Because of the influence of various subjective and objective factors, many colleges and universities have very narrow selection. The athlete students are confined to a small group, which makes the starting point of the athletes very low. Athletes from all corners of the globe have obvious difference in training level, technical level and life habits. In addition, the athletes are enrolled in a unified way and have good cultural foundation and understanding ability. They tend to be psychologically and physiologically mature and have great potential for development.

\section{Problems in Track and Field Training in Ordinary Colleges and Universities}

For the moment, the track and field teaching materials of ordinary colleges and universities in our country are still subject to tradition. The training emphasizes the competitive and technical nature but does not correctly deal with the relationship between sports technology and physical and mental health. It also ignores the difference between sports technology and sports skills. The improvement of the athletic skills is necessary for the students. And it is not easy to explain the theory and improve technology level in the general class which has less class hour when it is easy for the coach to ignore the overall quality of students and basic skills training.

As for the training objectives, due to that the new curriculum outline changed part of the course name, guiding ideology, teaching tasks and curriculum structure, the training purposes and application of track and field training are inconsistent in many colleges and universities and students can not feel the benefits for future work. Therefore, ordinary colleges and universities should reposition track and field training, update the teaching philosophy, so that track and field training can adapt to social development.

The continuous progress of modern science and technology makes the teaching technology be updated and developed. However, the track and field teaching and training mode of many colleges and universities in our country are still teachers' wall charts and demonstration and repetition of students. The means of track and field training are simple and not combined with the individual differences of students. Students' training enthusiasm was bruised because their learning enthusiasm is not high but always in a passive state, in which the personal characteristics can not get full play. Combined with the professional level of teachers and training conditions, it is difficult to achieve a comprehensive modernization on teaching methods.

According to the survey, due to the simple track and field training methods, boring training content, lack of training grounds and other reasons, the majority of students lack of interest and enthusiasm in track and field training. Some students worried that they can not pass the project test because of poor physical fitness, which seriously affected the enthusiasm and confidence of students in participating in track and field curriculum. In addition, the track and field training in ordinary colleges and universities are often for the purpose to reach the standard. The training content is monotonous and the technologies are difficult, so it is difficult to stimulate students' interest and enthusiasm.

For college and university athletes ,the usual training intensity is very large and the physical and psychological pressure of students are relatively large. Some students even faint in high-intensity training. In addition, because most of the university track and field training venues are in the 
outdoors, students may feel tired after the invasion wind and sun invasion. It is difficult for students to complete the training tasks to meet the training indicators and requirements through quantitative examination methods, which is complained by students that the training program is difficult, bitter and tired. Then students lack of interest in track and field training, and thus the training effect greatly reduced.

Adequate training and recovery time guarantee excellent results. However, in the ordinary colleges and universities, students not only need to do sports training, but also to ensure the completion of learning tasks, which limit track and field training in some way, thus affecting the training effects and achievements. According to the actual investigation, it can be seen that the main factor restricting the development of college track and field is the contradiction and conflict between learning and training. Different from the professional physical education institutions, the completion of studies is the primary task for ordinary college and university students and the spare time is spent on sports training. Especially in the junior and senior year, students need to prepare graduation thesis, entrance examination, internship, employment, etc. It is difficult for them to put heart and soul to sports training, which will seriously affect the training results.

At present, the overall quality of track and field coaches in China is not high. They lack of innovation awareness and ability, stick to the traditional training concepts and training methods, lack of relevant learning and communication of track and field training project, making it more difficult to master the development trend and training rules of track and field sports. In addition, the professional level of some track and field training coaches is low. Some coaches even just have switched to this profession, so the development of track and field sports is seriously affected.

To achieve good training results, it should be ensure that the training intensity and exercise load is of the right amount. From the training theory and training practice, in the track and field training process, the way to improve the athlete's adaptability is to increase the sports load. However, some coaches have neglected the athlete's physiological function, and have taken great athleticism and heavy physical fitness training for all athletes. There is no difference between their treatment to athletes of different levels, which not only can not increase the athlete's load, but also may hinder the improvement of grades and levels of athletes.

\section{Countermeasures of Perfecting Track and Field Training in Colleges and Universities}

As a versatile sport, track and field sports are the foundation of other sports. People who often engaged in track and field sports can not only promote the body's metabolism, regulate the human nervous system and visceral function, but also exercise the will of people's quality. The track and field training will play an irreplaceable role if taken full advantage of its characteristics. In addition to the rich application level, fitness methods and auxiliary means, the track and field sports is also easy to learn and requires low venue conditions, from which we can see the fitness value. To this end, we need to increase the propaganda of fitness value of the track and field sports, calling for more students to participate in it.

According to the characteristics of track and field training, it can be seen that a complete set of management system is necessary for track and field training. Therefore, before carrying out track and field training, a training program should be formulated at colleges and universities and strictly followed in the actual training process for systematic training to constantly improve the athletes' physical and mental quality, technical level and will quality. In addition, the management of ordinary colleges and universities can take track and field training into the education program to improve management system and achieve better training results.

(1) Developing a scientific track and field training program can help to improve the quality and effectiveness of training, thereby improving the athlete's skill. As an indispensable procedure for daily training, the training program has a certain purpose, which is conducive to improving the organization and procedure of track and field training. It is worth mentioning that before start training, coaches should fully grasp the physical condition of athletes, and develop a reasonable plan according to the curriculum, site conditions and weather conditions and other factors to assist 
the daily training, achieving the integrity and pertinence of track and field training.

(2) The mechanical training methods can be avoided according to the teaching concept, and individual characteristics. In other words, the coaches in colleges and universities should follow certain principles in the training, such as intuitive teaching, different treatment, reasonable arrangements for sports load, cyclical, motivational incentives, etc. In addition, the coaches need to adjust the training method to avoid damage to the athlete's body function according to the actual situation of each athlete.

(3) The efficiency of track and field training can be improved through special selection of training methods. As we all known, athletes can achieve best training results when full of physical strength. In order to keep the athletes' physical strength and save the limited time, coaches should use practical and effective training methods as much as possible. For example, the best way of throwing shot training is mastering the best posture followed by sideways sliding training.

According to the characteristics that college students have broad knowledge, good understanding and accepting abilities, students can be taught to carry out guiding ideology of track and field training. Specifically, when training students, teachers should not only impart technology and tactics, but also should help students understand and master other knowledge including the relevant sports psychology, nutrition and recovery, etc. Students' training motivation can be promoted and blind training can be avoided through mastering the knowledge of basic sports, competition and referee.

To achieve the sustainable development of sports, we should deal with the relationship between education and sport through combining sports and education. To this end, sports department in colleges and universities should be closely aligned with each other, achieving win-win between learning and training.

According to the experience of international sports, the development of sports is based on the cultivation of quality of coaches. Facing the current situation that college PE teachers have relatively low professional proficiency, colleges and universities should strengthen the training of coaches to improve their business and build a high-quality coach team, improving the effect of track and field training, so as to improve the level of students' sports.

\section{Conclusion}

In short, the development laws of should be followed in the track and field training of ordinary colleges and universities. We should mine the sports potentials of students, continuously improve their level of sports and enhance the influence of track and field sports, thus to promote the development and progress of the sports of colleges and universities.

\section{References}

[1] L. Yang. Problems in Track and Field Training in General Universities and Countermeasures[J]. Value Engineering, 2012, 31 (16) : 33-34.

[2] L. Y. Li. Analysis of Heilongjiang province college and university track and field training situation and research of sustainable development[J]. Journal of Science of Teachers' College and University , 2012, 32 (4) : 18-19.

[3] W. X. Wang and G. M. Yin. A Discussion of Health and Safety in University Athletics Training[J]. Journal of Baoshan Teachers College, 2014 (2) : 22-23. 